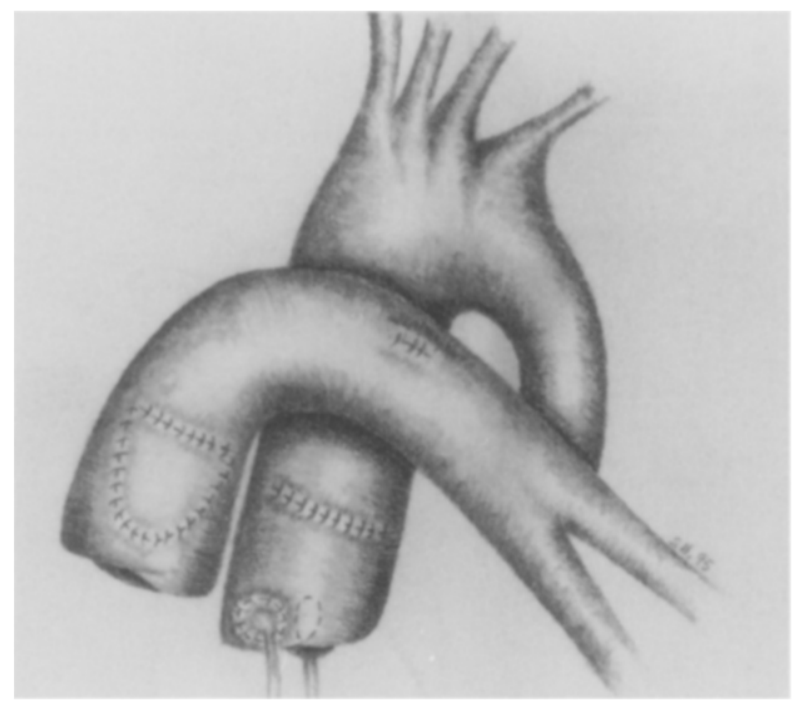

Fig. 2. Arterial switch repair with the great artery transection at the level of the APW and incorporation of defect margins into the arterial reanastomosis.

reported patch closure of the APW and ventricular septal defect concomitant with a Senning atrial baffle repair. Both of these infants were first seen and were operated on at older ages ( 7 and 3 months respectively) than our patient, and both were found at necropsy to have significant pulmonary vascular disease. Accelerated progression of occlusive pulmonary vascular disease has been associated with d-TGA, ${ }^{7}$ particularly when combined with a left-to-right shunt. ${ }^{8}$ Coexisting D-TGA and APW should manifest a similar propensity toward early development of pulmonary vascular changes. Pulmonary hypertension has been suggested as a significant risk factor when assessing operability of $\mathrm{APW}^{9}$ and may be a significant factor in the outcome of operations performed on older patients.

The surgical repair described here provides the advan- tages of a conventional arterial switch without extensive additional technical difficulty and is commonly performed before development of pulmonary vascular disease. Transection of the great arteries at the level of the APW in this case allowed the margins of the defect to be incorporated in the reanastomosis of the great vessels, and the coronary transfer could therefore be accomplished in the normal manner. A distal APW (Richardson type II or III) or an abnormality of coronary artery anatomy might not have been amenable to this surgical approach.

\section{REFERENCES}

1. Richardson JV, Doty DB, Rossi NP, Ehrenhaft JL. The spectrum of anomalies of aortopulmonary septation. J THORAC CARDIOVASC SURG 1979;78:21-7.

2. Elliott LP, Amplatz K, Edwards JE. Coronary artery patterns in transposition complexes. Am J Cardiol 1966;17:362-78.

3. Liebman J, Cullum L, Belloc NB. Natural history of transposition of the great arteries: anatomy and birth and death characteristics. Circulation 1969;40:237-62.

4. Van Praagh R, Jung WK. The arterial switch operation in transposition of the great arteries: anatomic indications and contraindications. Thorac Cardiovasc Surg 1991;39(Suppl):13850 .

5. Tiraboschi R, Salomone G, Crupi G, et al. Aortopulmonary window in the first year of life: report on 11 surgical cases. Ann Thorac Surg 1988;46:438-41.

6. Krishnan P, Airan B, Sambamurthy, Shrivastava S, Rajani M, Rao IM. Complete transposition of the great arteries with aortopulmonary window: surgical treatment and embryologic significance [Letter]. J ThoraC CARdIOVASC SuRG 1991;101:74951.

7. Kumar A, Taylor GP, Sandor GG, Patterson MW. Pulmonary vascular disease in neonates with transposition of the great arteries and intact ventricular septum. Br Heart J 1993;69:442-5.

8. Newfeld EA, Paul MH, Muster AJ, Idriss FS. Pulmonary vascular disease in complete transposition of the great arteries: a study of 200 patients. Am J Cardiol 1974;34:75-82.

9. van Son JA, Puga FJ, Danielson GK, et al. Aortopulmonary window: factors associated with early and late success after surgical treatment. Mayo Clin Proc 1993;68:128-33.

\title{
ANTERIOR TRANSLOCATION OF THE RIGHT PULMONARY ARTERY TO PREVENT BRONCHOVASCULAR COMPRESSION IN A CASE OF TRUNCUS ARTERIOSUS AND TYPE A INTERRUPTED AORTIC ARCH -
}

René Prêtre, $\mathrm{MD}_{,}^{\mathrm{a}}$ Beat Friedli, MD, ${ }^{\mathrm{b}}$ Jean-Claude Rouge, $\mathrm{MD},{ }^{\mathrm{c}}$ Afksendiyos Kalangos, $\mathrm{MD}, \mathbf{P h D},{ }^{\mathrm{a}}$ and Bernard Faidutti, MD, ${ }^{a}$ Geneva, Switzerland

The normal aortic arch produces a wide and harmonious curve that encircles the origin of the right pulmonary

From the Service de Chirurgie Cardio-vasculaire, Département de Chirurgie, ${ }^{a}$ Unité de Cardiopédiatrie, ${ }^{b}$ and Unité d'Anesthésiologie Pédiatrique, ${ }^{\mathrm{c}}$ Hôpital Cantonal Universitaire, Geneva, Switzerland.

Accepted for publication May 22, 1995.

J Thorac Cardiovasc Surg 1996;111:672-4 artery and the left pulmonary main bronchus. Relative shortening of the ascending or descending aorta (for instance after an arterial switch for transposition of the great arteries or after direct repair of a type A interrupted aortic arch) may produce a compression of these ele-

Copyright (C) 1996 by Mosby-Year Book, Inc. $0022-5223 / 96 \$ 5.00+0 \quad \mathbf{1 2 / 5 4 / 6 6 6 0 8}$ 

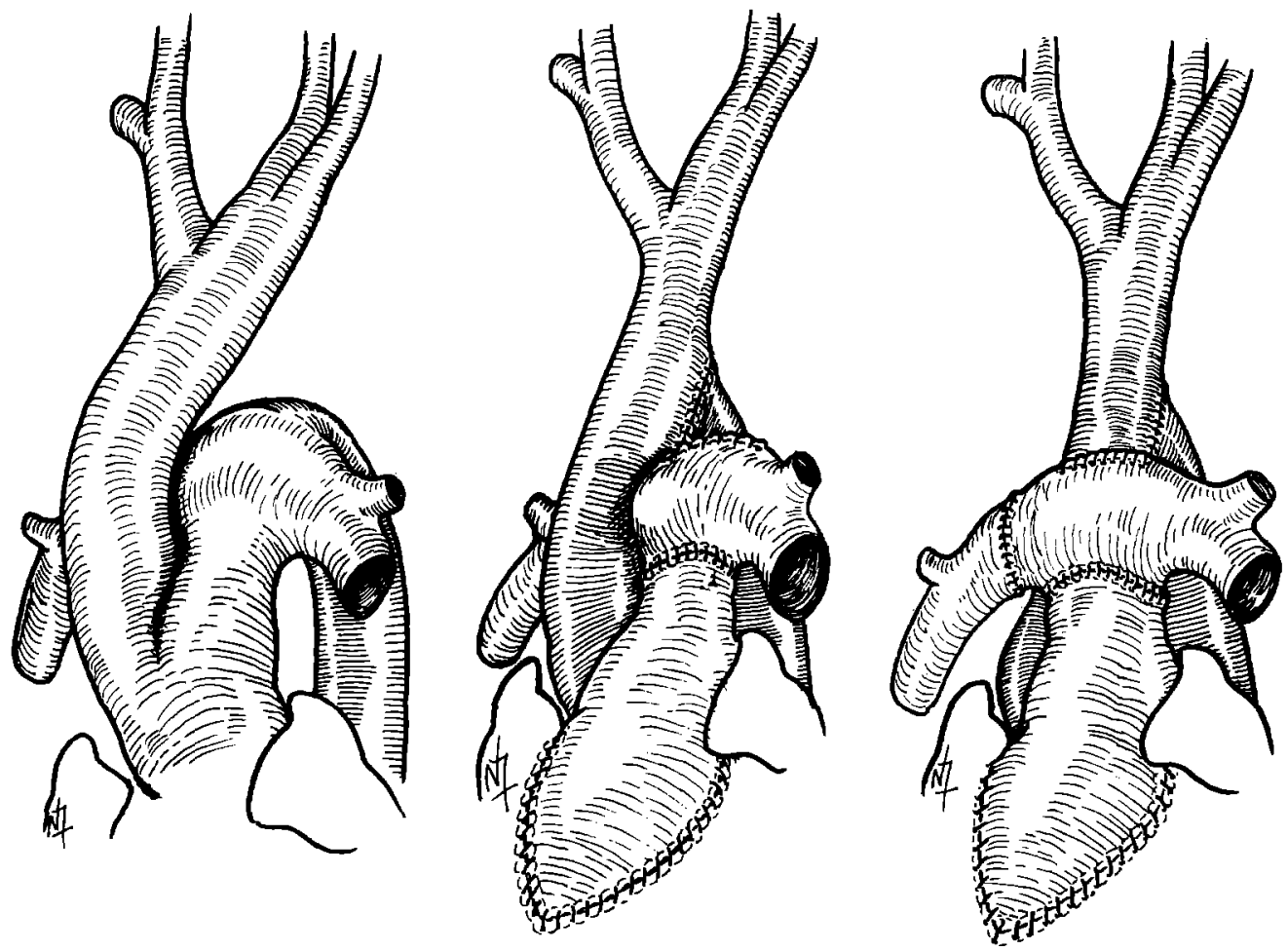

Fig. 1. Left, Relationship between the great arteries. The origin of the descending thoracic aorta has a caudal direction. Middle, Schematic representation of the potential compression of the right pulmonary artery after surgical correction. The descending thoracic aorta, connected to the underface of the ascending aorta, creates a narrow neoaortic arch. Right, Anterior translocation of the right pulmonary artery over the ascending aorta prevents compression of the origin of the right pulmonary artery and provides more space for the left main bronchus.

ments. Anterior translocation of the right pulmonary artery over the aorta prevents its compression and seems recommended in some cases of type A interrupted aortic arch. A case of anterior translocation of the right pulmonary artery over the aorta during initial repair of a type 1 truncus arteriosus and a type A interrupted aortic arch is presented. This maneuver (akin to the Lecompte maneuver $^{1}$ ) should be considered in some cases of interrupted arch to avoid compression of the right pulmonary artery or of the left main bronchus.

A 5-month-old infant was transferred to our institution from a nonindustrialized country for failure to thrive and multiple episodes of cardiac decompensation. On admission on November 7, 1994, a type 1 truncus arteriosus with a perimembranous restrictive ventricular septal defect and type A interrupted aortic arch was diagnosed (Fig. 1, left). A few days after admission, intubation was necessary because of bronchopneumonia and pulmonary edema. The patient was put on an emergency list for a small-sized homograft. Controlled hypercapnia and hypoxemia were maintained to keep a balanced ratio between the pulmonary and systemic resistance. As soon as a homograft became available, the patient underwent a corrective procedure (surgeon, B. F.) with cardiopulmonary bypass and a 15-minute hypothermic circulatory arrest. The ventricular septal defect was enlarged and an internal hemitube of polyester fiber was used to connect the left ventricle to the truncal valve. The ductus was divided, the descending aorta was mobilized as much as possible, and the descending aorta was directly anastomosed under the ascending aorta. This maneuver produced a posterior displacement of the ascending aorta, with a significant reduction of the space between the ascending and the descending aorta. It became evident that the right pulmonary artery would become constricted by the neoaortic arch (Fig. 1, middle). The origin of the right pulmonary artery was therefore divided, brought up in front of the truncal root, and sutured back onto the pulmonary bifurcation. This maneuver was easy to perform because the right pulmonary artery was dilated. A $13 \mathrm{~mm}$ aortic homograft was used to connect the right ventricle to the pulmonary bifurcation. The postoperative course was uneventful, although partial compression of the left pulmonary bronchus was documented by broncoscopy during the first 15 postoperative days. Three months later, magnetic resonance imaging showed no compression of the bronchus (Fig. 2), and the child was free of symptoms.

Compression of the pulmonary arteries or tracheobronchial tree is a recognized complication after corrective operations on ventriculoarterial connection anomalies. Before the Lecompte maneuver was introduced, this complication was encountered after an arterial switch for 


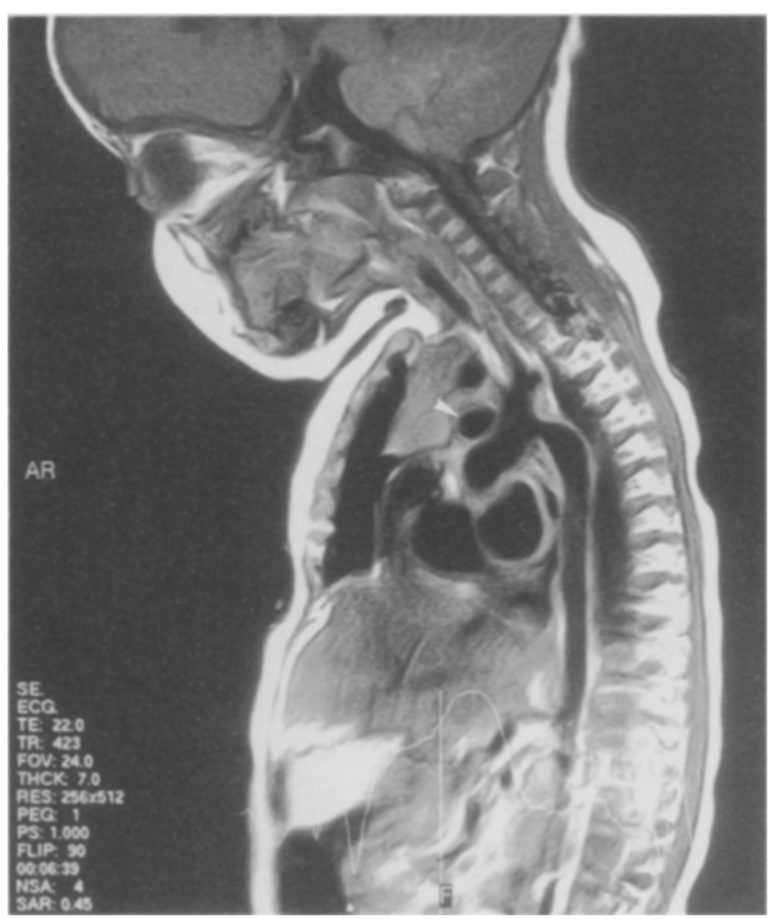

Fig. 2. Magnetic resonance imaging study showing the anterior translocation of the pulmonary artery (arrow) over the truncal root and the narrow space within the neoaortic arch. Note the posterior concavity of the ascending aorta.

transposition of the great arteries, especially when the arteries had an anteroposterior arrangement. Similarly, this complication has also occurred after one-stage repair of truncus arteriosus with interrupted aortic arch. ${ }^{2,3}$ In both situations, the corrective procedure pulls the ascending aorta posteriorly. The proximal part of the ascending aorta is brought deep (as the neoaorta) on the aortic root in the case of transposition, and the middle or distal part of the ascending aorta is tracted posteriorly by the descending aorta (sutured to its underface) in the case of type $\mathrm{A}$ interrupted aortic arch. In this type of interrupted arch, the descending aorta is not connected to any brachiocephalic artery and curves immediately posteriorly and caudally from the ductus arteriosus (Fig. 1, left). Even after appropriate mobilization, the descending thoracic aorta may reach only the middle part of the ascending aorta and may create a significant posterior traction on the ascending aorta. The curve of the newly constructed aortic arch is less ample, and the space between the ascending and descending aorta is narrowed (Fig- 1, middle and right). Measures aimed at reducing the risk of a bowstring effect on the right pulmonary artery or left main bronchus include a wide mobilization of the ascending aorta, head vessels, and descending aorta, or interposition of a graft between the ascending and the descending aorta. Anterior translocation of the pulmonary artery over the aorta prevents compression of the pulmonary arteries (mainly the right pulmonary artery) and leaves the left main bronchus alone to occupy the narrow space between the ascending and the descending aorta (Fig. 1, right). In January 1995, Rao and coworkers ${ }^{4}$ reported a patient who, after one-stage repair of truncus arteriosus with a type B interrupted arch, had compression of the right pulmonary artery. The compression was relieved during a second operation by transposing the right pulmonary artery in front of the ascending aorta. As in our case, anterior translocation of the right pulmonary artery should be considered during the initial operation of a one-stage repair of a truncus arteriosus associated with a type A interruption of the aortic arch. In this situation, the pulmonary arteries are usually dilated and the connection of the descending to the ascending aorta (the truncal root) is frequently performed at a more caudal level than in the other types of aortic arch interruption. In type B interrupted arch, pulmonary translocation should probably be considered if compression of the right pulmonary artery is considered likely.

\section{Addendum}

Unfortunately this child died in April 1995, 5 months after the operation. There was no opportunity for a postmortem diagniosis.

\section{REFERENCES}

1. Lecompte Y, Zannini L, Hazan E. Anatomic correction of transposition of the great arteries. New technique without use of a prosthetic conduit. J THORAC CARDIOvaSC SURG 1981;82: 629-31.

2. Hazekamp MG, Quaegebeur JM, Singh S, et al. One stage repair of aortic arch anomalies and intracardiac defects. Eur J Cardiothorac Surg 1991;5:283-7.

3. Sano S, Brawn WJ, Mee RB. Repair of truncus arteriosus and interrupted aortic arch. J Cardiac Surg 1990;5:157-62.

4. Rao IM, Swanson JS, Hovaguimian H, McIrvin DM, King $\mathrm{DH}$, Starr A. Anterior pulmonary translocation for repair of truncus arteriosus with interrupted arch. Ann Thorac Surg 1995;59:216-8. 